\title{
Role of Mental Health in understanding and Preventing Suicide
}

\author{
Smita Satapathy ${ }^{1}$, Madhubrata Mohanty ${ }^{2}$

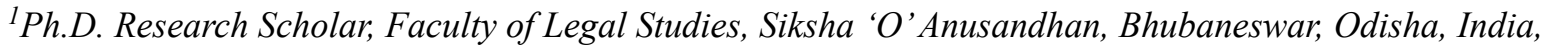 \\ ${ }^{2}$ Associate Professor, Faculty of Legal Studies, Siksha 'O'Anusandhan, Bhubaneswar, Odisha, India
}

\begin{abstract}
Suicide is an important mental health problem in our society, as it is in most of the world's developed nations. It's an affliction that robs us of some of our community's most active leaders. It is a most troubling type of mental disease to imagine, a mental disorder in which the victim's pain and fear causes him to prefer death to his misery. Suicide is widespread. Most communities have earlier treated suicide as a felony and have instituted laws to restrict the act and prosecute those who attempt it whereas the notion have changed and now individuals who try or commit suicide are frequently viewed as depressed or mentally unstable. This Covid(Corona virus) pandemic had made the situation worse because many people are taking help from professionals for the first time due to severe increase of anxiety and stress. During this lockdown period many have developed suicidal tendencies and seeking physicians' help. After the suicide of famous bollywood actor Sushant Singh Rajput many are talking about the mental health awareness. In this present paper we will analyze the problem of suicide, mental health care laws and suicide regulation and some strategies for suicide prevention.
\end{abstract}

Keywords: Suicide, Mental Health, Suicide prevention.

\section{Introduction}

"There are many pointless deaths but never a needless suicide. Every suicidal act is addressed to certain unfulfilled needs" -Shneidman Edwin

Man is brought into the world free but wherever he is in chains. Suicide has been perceived as a noteworthy general medical issue. WHO recognizes that suicide is a worldwide issue influencing all countries. Suicide adversely affects the individuals who murder themselves as well as on families, networks and on society. WHO perceives that numerous deaths from suicide are incautious and require successful, exhaustive, multi pectoral reactions and national systems for avoidance. ${ }^{1}$

\footnotetext{
Corresponding Author:

Dr. Madhubrata Mohanty

Associate Professor, Faculty of Legal Studies, Siksha 'O' Anusandhan, Bhubaneswar, Odisha, India

e-mail: madhubratamohanty@soa.ac.in
}

According to the recent report published in "Crime in India 2018 Statistics (National Crime Records Bureau, Ministry of Home Affairs) under the Chapter II (Suicide in India) recorded a total of $1,34,516$ suicides were reported in the country during 2018 showing an increase of $3.6 \%$ in comparison to 2017 and the rate of suicides has increased by 0.3 during 2018 over 2017." ${ }^{2}$ Each suicide is a personal tragedy that prematurely takes the life of an individual and has a continuing ripple effect, dramatically affecting the lives of families, friends and communities. Every year, more than $1,00,000$ people commit suicide in our country. There are various causes of suicides like professional/career problems, sense of isolation, abuse, violence, family problems, mental disorders, addiction to alcohol, financial loss, chronic pain etc. NCRB collects data on suicides from police recorded suicide cases. From this it is clear that police recorded cases does not include the unreported cases and in India many suicide cases are not reported and mainly the attempted cases are reported minimal because attempt to commit suicide is still considered an offence. According to the $\mathrm{WHO}$, around 8 lakhs people die of suicide every year and up to 25 times as many make a 
suicide attempt. And in 2018, National Crime Records Bureau provides that the average rate of suicide in India is 10.2 .

Since the laws of mental health treatment have focused on mental illness/psychiatric rhetoric to describe suicide, it would be misleading to argue that suicide is medicalized in India with the passing of this Legislation. Efforts to discourage suicide in general mental health provide a more complicated definition of suicide prevention than the rules of mental health. While the national mental health policy approach to suicide prevention has been to conceptualize suicide as predominantly a health concern, it nevertheless deals with non-health, non-medical activities such as restricting pesticide exposure, or promoting 'high-risk' urban space monitoring as approaches for suicide prevention. ${ }^{3}$ Transnational and national public policy programs in seeking such a strategy should not view suicide solely through the prism of mental disease. As public health programs also adopt a psychosocial approach which takes into account social, cultural and economic issues when developing interventions. Including suicide as a public health issue, prevention of suicide needed to be viewed not only as a human mental disorder but by certain systemic forms of prevention. Psychiatric policy and medicinal practice is a traditional capitalist system of control capable of ruling through the wellbeing of the communities. ${ }^{4}$ The claim that in contemporary India such a change to the suicidal person's medical services is illustrative of attempts to manage the suicidal person by therapy may be made. Yet, as we have learned, the current dialogue on suicide and mental illness is just part of the picture.

Objective: The present article attempts to analyse the importance of the problem of suicide and the role of mental health in understanding and preventing suicide.

The Problem of Suicide: The importance of the problem can be measured in numbers, in value of the lives lost and in the suffering of the suicide victim and those who knew about him. Suicide is indeed a complex issue encompassing philosophical, ethical, legal and practical dilemmas. It needs open debate with due consideration to different aspects and points of view. Lack of precise measures to detect mental illness is not a sufficient reason to assume all suicides are due to abnormal mental states. It must be a drive towards developing measures that enable us to detect and exclude mental illnesses with more confidence and certainty. The subject of suicide is painful and often an avoided area for consideration or discussion. Many feel it is a morbid issue and that talking about it may only stir up interest and perhaps increase the incidence. Attitudes towards studying, understanding and preventing suicide vary but there is an increasing concern about the problem and willingness to face it. ${ }^{5}$

In India, suicides are more of a medico-legal problem than a health or societal problem. Hence information on suicides is collected and compiled by police departments. In developing countries like India, a number of factors related to culture, family life, education, growing aspirations and inability to tolerate negative feelings contribute in a big way for suicides. Various research studies state that biological, genetic, and psychosocial risk factors for suicide may in many cases not confer risk directly, but indirectly, through lack of social support, stressful life events, depression, hopelessness and suicidal intention which ultimately increases risk for suicidal behaviour. The most promised risk factors are a prior suicide attempt and mental illness. Research indicated that $90-95 \%$ of people who die by suicide had at least one diagnostic mental disorder, particularly including depression, bipolar disorder, borderline personality disorder, and substance dependence or abuse. ${ }^{6}$

Mental Health Care Laws and Suicide Regulation: Prevention of suicide within mental health care discussion is not a special thing in itself. As demonstrated, suicide avoidance and public health discourse encompasses psychiatric/biomedical, psychological, and psychosocial interventions. But, unlike the discourses that went into criminal law debates, where there were no limits on what conversation could affect a legal judgment, there are clear limitations in mental health care discussions. Initiatives for mental health care, not only psychiatric/ pharmacological but also psychosocial programs, regularly concentrate clinical dialogue and specialists in their suicide prevention mandate. Discourse on mental health treatment has driven changes in suicide laws. Law reform attempts have been made to decriminalize attempted suicide, and portray all suicides as a question of mental health. ${ }^{7}$

Post-independence, there were two significant laws in India which had an effect on mental health treatment. The Mental Health Act -1987 (MHA) has given a legal protection for mentally ill people and the Persons with Disabilities (Equal Opportunities, Protection of Rights 
and Full Participation) Act - 1995 (PWD) provided a basic standard of care for those with intellectual disorders, including mental illness with a disability classification. All of these legal provisions, however, faced criticism from mental health care providers, human rights activists, and disability scholars.

Mental Health Care Bill-2013 and 2016: The Mental Health Care Bill (MHC)-2013 is an attempt to reform Indian mental health carelaws.

"With regard to the legal regulation of suicide, Section 124 of the MHC Bill-2013 states:

1. Notwithstanding anything contained in Section 309 of the IPC, any person who attempts suicide shall be presumed, unless proved otherwise, to be suffering from 'mentalillness' at the time of the bid and shall not be liable to punishment under the said sections.

2. The appropriate Government shall have a duty to provide care, treatment and rehabilitation to a person, having mental illness and who attempted to commit suicide, to reduce the risk of recurrence of attempt to commit suicide".

The bill does not amend Section 309 IPC in saying this but presumes that committing suicide is a symptom of mental illness. Under this Section 124 term, a person contemplating suicide would be spared from criminal prosecution but considered to be "mental disorder suffering."

The 2013 MHC Bill was praised by numerous medical clinicians for portraying suicide as a mental disorder.

Firstly, they argued that this new conceptualization would benefit those people who attempt suicide because of stress; secondly, by not involving the police and instead putting them under the protection of mental health practitioners, the new bill was seen as more responsive to the needs of individuals who attempt suicide and thirdly, under the newmedical framing of suicide, families where someone has attempted suicide would be more willing to report the incident since they no longer have to report to the police. ${ }^{8}$

"With regards to the implications of Section 309 IPC, Salelkar and Davar explain that, asper MHC Bill 2013, a person who attempts suicide is exempt from punishment but notprosecution. Thus, the police continue to have the authority to remand a person who has attempted suicide into custody and produce them in front of the Magistrate. Since the law would assume that such a person is suffering from mental illness, s/he could be sent to a public mental establishment for assessment and treatment, or mandated to remain in a mental health establishment for up to ten days (Salelkar \& Davar, 2013; Section 111, MHC Bill 2016)."

The Mental Health Care Act, 2017: In India, the Mental Healthcare Act (MHCA) 2017 was passed on April 7, 2017 and enforced on May 29, 2018. This is "an Act to provide for mental healthcare and services for persons with mental illness (who have substantial disorder and whose functioning is grossly impaired) and to protect, promote and fulfil the rights of such mentally ill persons (who have substantial disorder and grossly impaired functioning), during delivery of mental healthcare services and for matters connected therewith or incidental thereto."

Until now, an attempt to commit suicide was a criminal offence as per Section 309 of Indian Penal Code (IPC), 1860. It is worth remembering here that the words "mental illness," which was used in a previous draft of the MHCA in 2013, was replaced by "severe stress," in 2016, by the Indian Parliament in MHCA 2017 after a lot of deliberations after considering the stigma and abetment laws associated with attempted suicide.

Section 115 of The Mental Health Care Act, 2017 specifically provides Presumption of severe stress in case of attempt to commit suicide-

"Notwithstanding anything contained in Section 309 of the Indian Penal Code any person who attempts to commit suicide shall be presumed, unless proved otherwise, to have severe stress and shall not be tried and punished under the said Code. The appropriate Government shall have a duty to provide care, treatment and rehabilitation to a person, having severe stress and who attempted to commit suicide, to reduce the risk of recurrence of attempt to commit suicide."

This provision impliedly repealed Section 309, the Indian Penal Code of 1860 which penalises attempted suicide. It is submitted that the legislators have realized, though belatedly, that suicidal tendency is an aspect of mental illness, and that such a person needs treatment in mental asylum rather than prison sentence.

There is no single change from one mode of control to another in the story of suicide regulation in India. 
Many life-management strategies exist in tandem. In India there coexists religion, legal (criminal and mental health laws), disability, political, cultural, caste violence among other suicide discourses. Therefore, the basis for suicide legislation does not lie exclusively within the rules of criminal justice, mental health care regulations or the debate of general mental health. However, though many discourses are at stake in debates on suicide, the debate on mental health is expanding rapidly. The campaign for mental health (from the global north as well as inside India) has described suicide as a result of mental illness, which should not then be criminalised. ${ }^{10}$

Suicide Prevention: With the evolving times, the issue of suicide was seen progressively like a worldwide issue and the World Health Organization has concerning attempted suicide empowers attempts for the prevention of suicide and communicated the view that rebuffing with detainment a conduct subsequent to either a psychological issue or a social trouble gives totally an off-base message to the populace. The International Association for Suicide Prevention has likewise communicated the view that attempted suicide ought to be decriminalized and that self-destructive people should be aided and detainment just aggravates their issues. ${ }^{11}$ And in pursuit of their objective, the Association made September 10 as "World Suicide Prevention Day."

Preventive programs should therefore be planned with a view to reducing factors which increase the probability of suicide attempts and which factors aimed at fostering resilience. Certain steps can be taken ${ }^{12}$ -

i. Effective diagnosis of psychiatric illnesses and successful treatment are highly significant.

ii. Improved $24 \times 7$ Suicidehelp-lines will help people deal with difficult circumstances that cause severe distress.

iii. Services for care and prevention should be adapted to the needs of specific age groups.

iv. Spreading information among people about risk factors, warning signs and recovery and preventive approaches is imperative.

v. Restricting exposure to common suicide strategies and preventing the use of extremely lethal method are without doubt necessary.

vi. Educational and religious institutions will play a crucial role in the effective and efficient delivery of preventive programmes. vii. To promote fair media reporting, much focus should be put on the idea that suicide is a pointless way to solve problems.

viii. High-risk people should be aimed at preventive programmes.

Individuals have no influence over the ups and downs of life, but keeping a good outlook will certainly improve the willingness to take them in action even in the face of adverse circumstances. There's nothing more valuable than life and suicide will never fix the problem.

\section{Conclusion}

Mental illnesses are considered to be closely linked to suicide. Diagnosed mental illnesses, particularly depression, are very common in persons attempting suicide. Similarly, drug dependence is closely related to suicide. Given ample clinical research associating treatable mental illness with suicide, the country's access to medical services remains weak and this confuses the issue. The new Indian Mental Healthcare Act passed by the parliament suggested that attempt to commit suicide has been impliedly decriminalised. It has made the government duty bound to provide medication, diagnosis and recovery to a person who has attempted suicide because of extreme stresses. This is a welcome step and might strengthen the suicide prevention strategies which are almost nonexistent due to poor resources both in terms of trained workforce and budgetary allocations. Whereas even after the brave attempt by the Mental Health Care Act to partially decriminalize suicide in 2017, the sad statement on the nation is that decriminalization can only become absolute if Section 309 is complete deleted from Indian Penal Code, 1860. What's needed is what Britain did in Suicide Act, 1961, the complete decriminalization of attempted suicide. Every police man today knows if you fail suicide attempt he will take you into custody under Section 309, IPC, but nobody in the police knows that there is a clause in the Mental Health Care Act 2017 that actually decriminalizes attempted suicide. Therefore, awareness of the Mental Health Care Act is the need of the hour. And there should be set up of a National Suicide Prevention Council with experts from a wide cross-section of society without much loss of further time. It is time the nation adopt a Zero Suicide India Plan.

Ethical Clearance: Not required, as the article is based on aspects which are doctrinally taken.

Source of Funding: Self 


\section{Conflict of Interest: Nil}

\section{References}

1. World Health Organization. Preventing Suicide: A Global Imperative. Geneva: World Health Organization. 2014.

2. National Crime Records Bureau. Accidental Deaths and Suicides in India: 2018. New Delhi, India: Ministry of Home Affairs, Government of India. 2018.

3. Bagcchi S, Chaudhuri P. Suicide and the law in India. BMJ. 2013; 347 (f6975). DOI:10.1136/bmj. f6975

4. Das A, Rao M. Universal mental health: Reevaluating the call for global mental health. $\mathrm{CPH}$. 2012; 22(4): 383-389.

5. Jacob KS. Suicide in India: Part perceptions, partial insights, and inadequate solutions. NMJI. 2017; 30(3): 155-158.

6. Vijayakumar L. Indian research on suicide. IJP. 2010; 52:S291-6.
7. Salelkar A, Davar B. Submission to the standing committee on Mental Health Care Bill of 2013 with reference to the treatment of persons who have attempted suicide. 2013, September 30. Retrieved From http://inclusiveplanet.org.in/sites/default/ files/MHC\%20Bill\%20Reccomendations $\% 20$ to $\% 20$ Standing $\% 20$ Committee $\% 20$ on $\% 20$ Suicide. pdf

8. Vadlamani LN, Gowda M. Practicalimplications of Mental Healthcare Act 2017: Suicide and suicide attempt. IJP. 2019; 61:S750-5.

9. AllyouNeedtoknowabouttheNewMentalHealthcare Bill. 2016. Available from: https://www.livelaw.in/ need-know-new-mental-healthcare-bill-2016.

10. Ministry of Law and Justice. The Mental Healthcare Act; Gazette of India. 2017. Available from: http://www.egazette.nic.in/Write ReadData/2017/175248.pdf.

11. Gupta R, Jain N. Prevention of suicide. IJSP. 2017; 33:139-41.

12. Vijaykumar L. Suicide and its prevention: The urgent need inIndia. IJP. 2007; 49:81-84. 